\title{
محددات المكانة الاجتماعية للأسر الريفية في بعض القرى المصرية
}

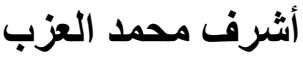 \\ أستاذ علم الاجتماع الريفي المساعد - جامعة كفر الثيخ-مصر
}

Received: Aug. 8, 2017

Accepted: Aug. 20, 2017

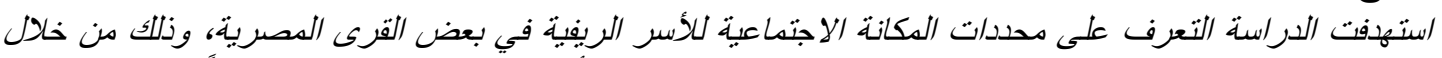

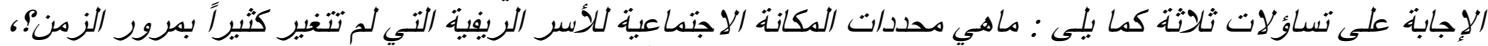

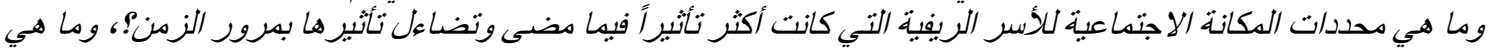

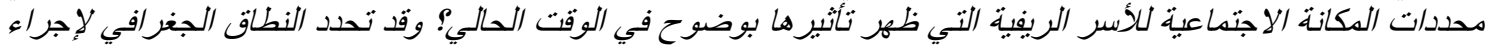

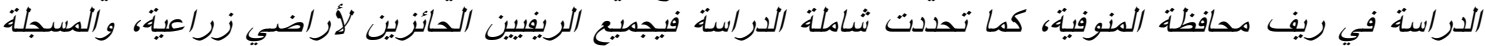

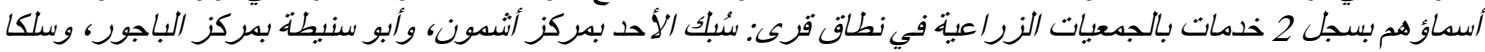

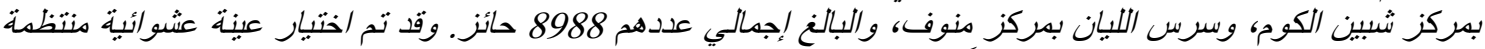

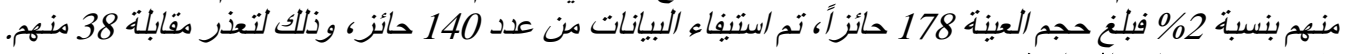
وقد تبين من نتائج العراسة:

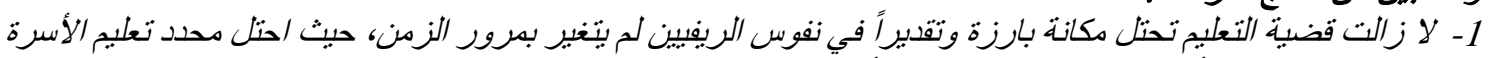

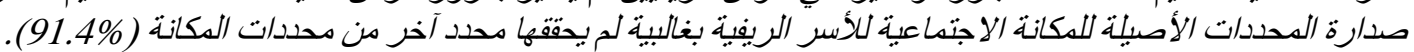

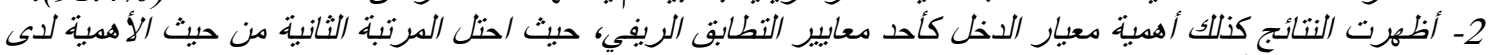
قرابة 86\% من أفراد عبنة الدراسة. 3ـ الملاحظ أن معليار حجم الحيازة الزراعبة قد احتل مرتبة متأخرة نوعاً ما مقارنة بععايير التعليم والدخل والسمعة، حيث

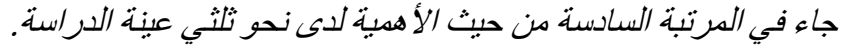

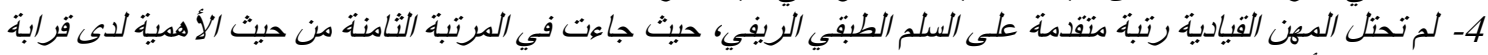

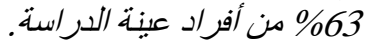
5- احتل معباري حجم الحبازة الحبيوانية، وحالة الدسكن المرتبتين قبل الأخبرة، والأخبرة على الترتبيب كمددات طبقية ريفية أصبلة.

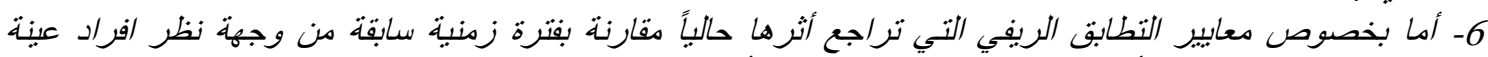

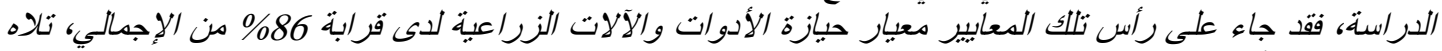

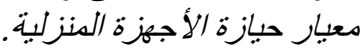

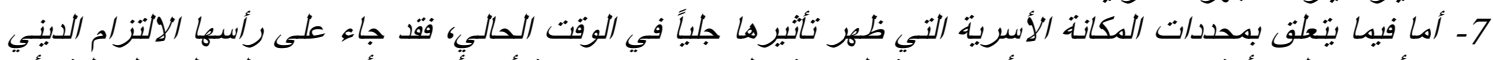

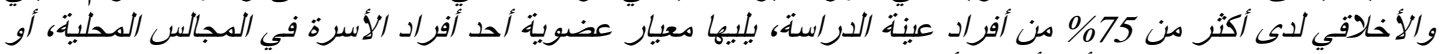

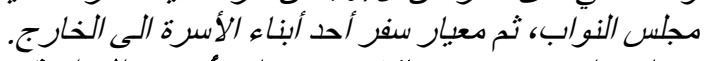

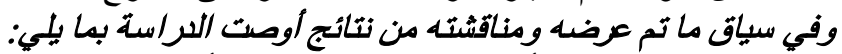

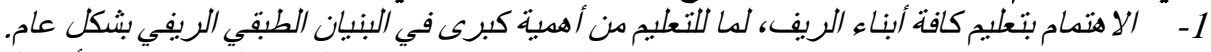

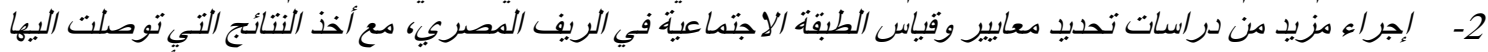

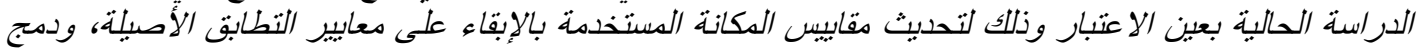

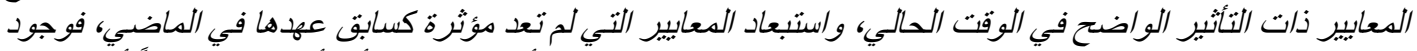

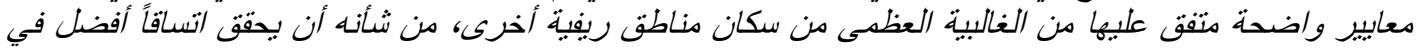

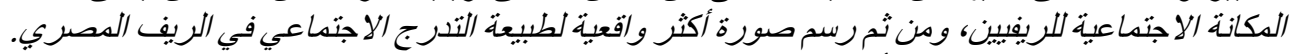
الكلمات الدالة : الككانة الإجتماعية ـ الأسر الريفية - التطابق الإجتماعى الريفى التئي

التوزيع الهرمي حيث يحتل عدد من الأفراد أو الجماعات

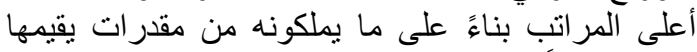
المجتمع وفقاً لمعاييره و احتياجاته.

وتخضع العلاقات الاجتماعية التي تقوم بين الناس

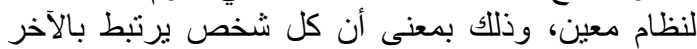

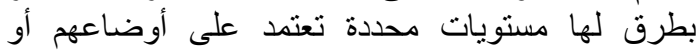

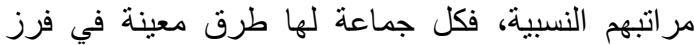
أعضائها، وتحديد أفضليتهم داخل الجماعة، وقليليل من فن فرن
مقدمة الدراسة

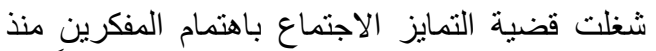

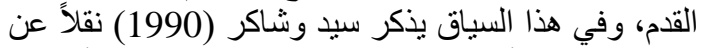
جامع و آخرون أن الغالبية العظمى من المفكرين قد أدركت

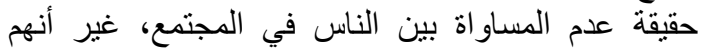

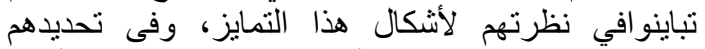

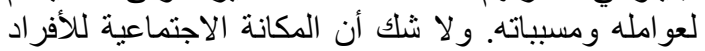

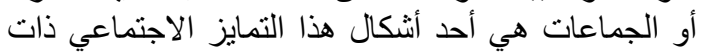




\section{A. M. Al-azab}

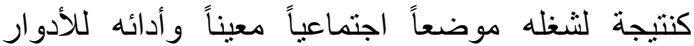

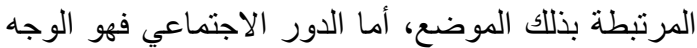

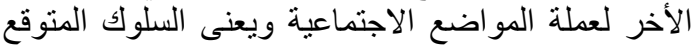

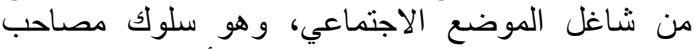

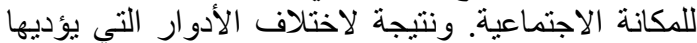

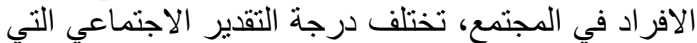

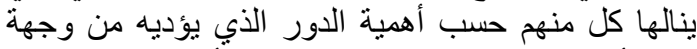

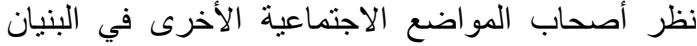

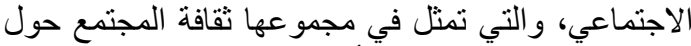

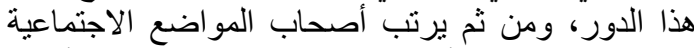
المختلفة في درجة أهمينها الآخرين حسب درب درجة أهمية الهية

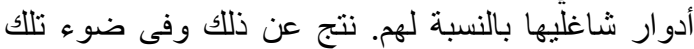

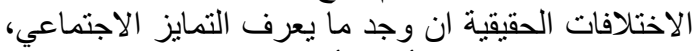

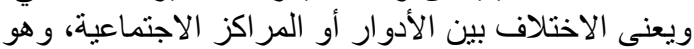

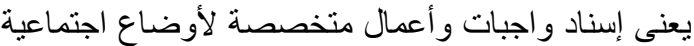

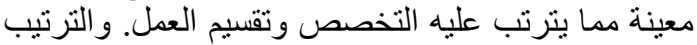

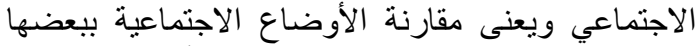

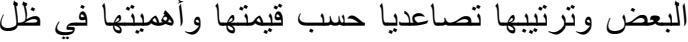
الثقافة السائدة في المجتمع.

ويذكر البياتي (2008) نقلاً عن مدكوره أن المكانة

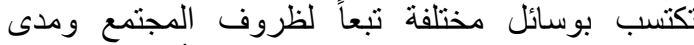

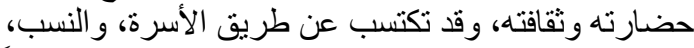

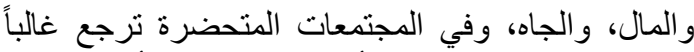

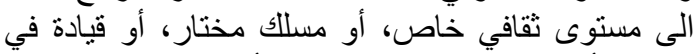

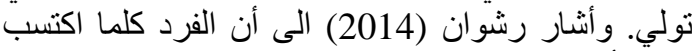
مكانة أكبر خارج الجماعة، ساعد ذلاعلك على ألى اكتسابه مكانة

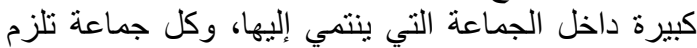

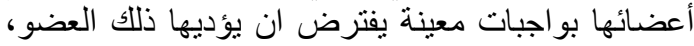
وكلما زادت مساهمة العضو في إنتاجه وكفاءتهاته، كلما نال

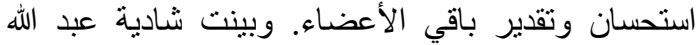
(2012) أن هناك تصوران لإلرجاع الأباء المكانة الاجتماعية

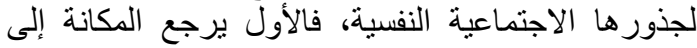

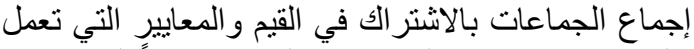

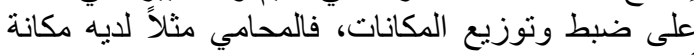
أعلى من السباك، وذللك حسب القيم و المعايير في تصور

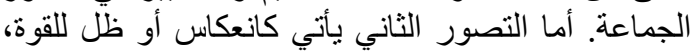

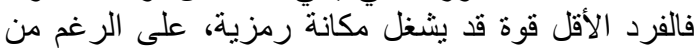
قناعته أنها أقل تقدير.

وقد أكد الطويل، و التو ايهة (2001) أن المهنة من أهم الهم

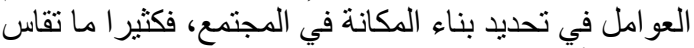

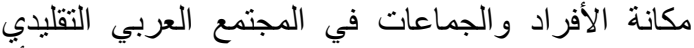

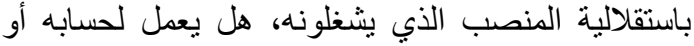

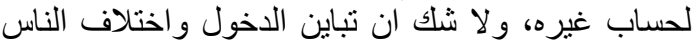
من حيث درجاتهم العلمية والتعليمية، ومن حيث التيث الأعمال

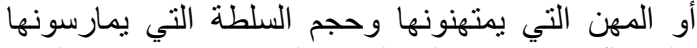

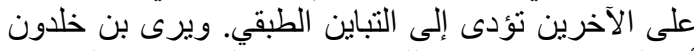

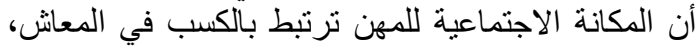

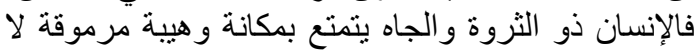
يتمتع بها فاقد الجاه، لأن الناس بعتمدون على مالهم

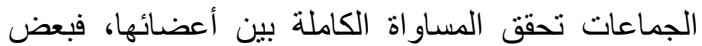

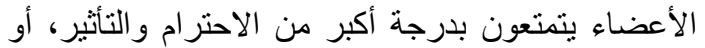

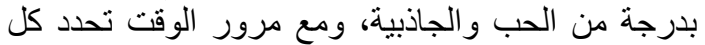

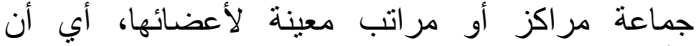
الأعضاء يكتسبون مكانة معينة من الجماعة (رشوان،

.2014

وفى قاموس علم الاجتماع عرفت المكانة الاجتماعية

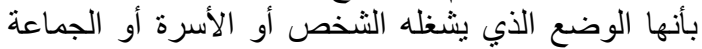

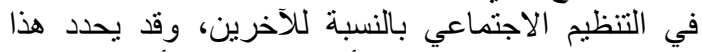

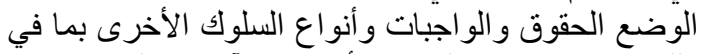

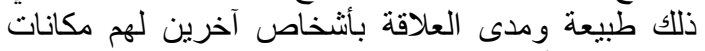

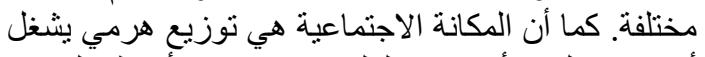

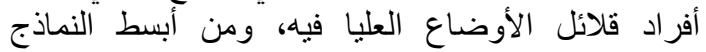

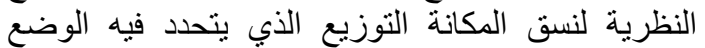

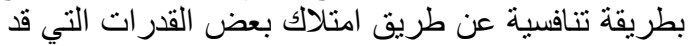

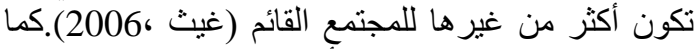

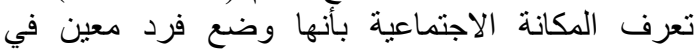

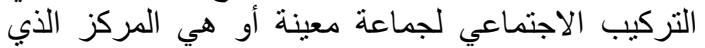

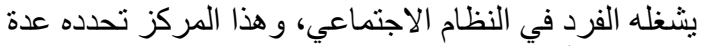

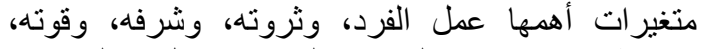

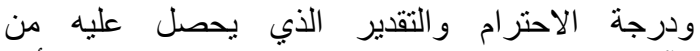

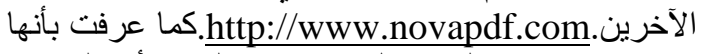
حقوق وواجبات الفرد على مستوى النسق أو المجتمع

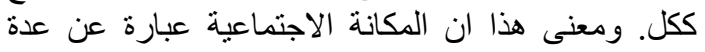

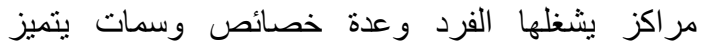
http://bohoot.blogspot.eg/2d4/11/blog-بهان .post_865.html

كما تعرف في الأدبيات الاجتماعية بأنها الموقع المرتبط بتوزيع وتعيين الاعتبار ات داخل دانل نظام اجتماعي معين، واحياناً بالنسبة لتحديد الحقوق والإن والالنزامات و النفوذ

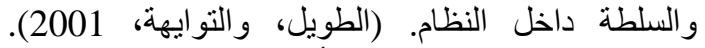

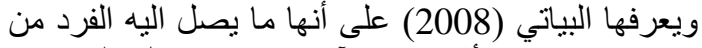

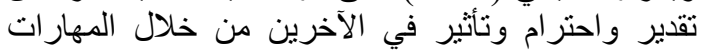

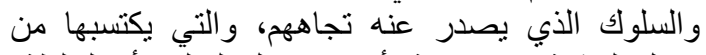
خلال التنشئة الاجتماعية، أو من خلال التعليه، أو التهلئه السلطة،

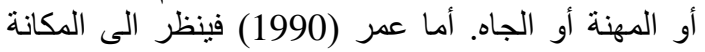
الاجتماعية بوصفها مرتبة وموقع اجتماعي يشغله الانسان

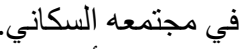
وتثثبر أدبيات علم الاجتماع و ولم النفس الاجتماعي

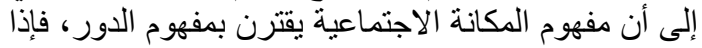

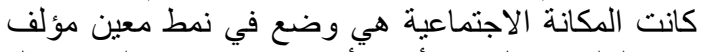

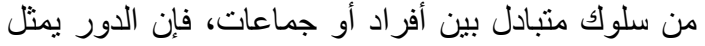

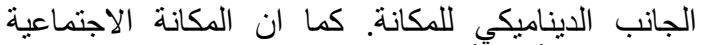

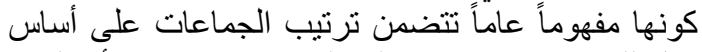
قابل للموازنة، فهو يشير إلى المسافة الاجتماعية أو الهيبة الهيبة

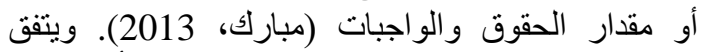

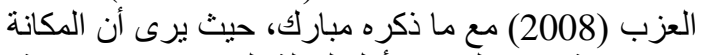

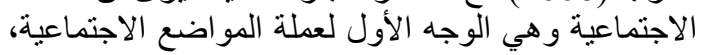
إذ تمثل جانب الحقوق بمعنى آخر التقدير الذي يناله الفئ الفرد 


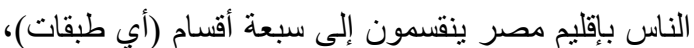
القسم الأول هم أهل الدولة، و القسم الثاني وهم أَّل الثل اليسار

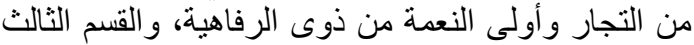

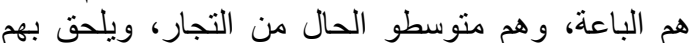

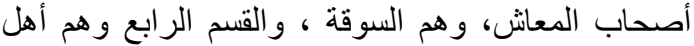

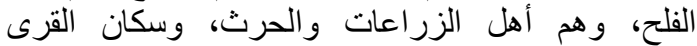
و الريف، ويأتي بعد ذللك القسم الخامس، وهم الفي الفهاء وطلاب العلم، وشمل القسم السادس أرباب الصناب الصنائع

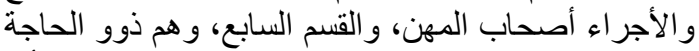

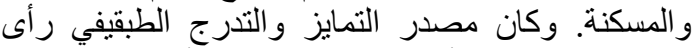

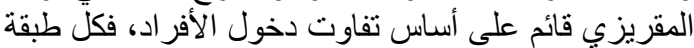

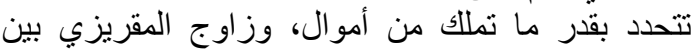

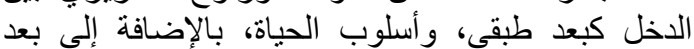
المهنة (فرحات، 2007).

وفى القرن التاسع عثر ألمح "كلود بك" في كتابه

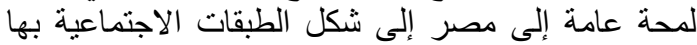

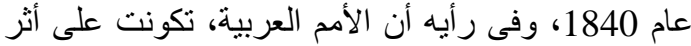
تخلصها من الغارات واته والفتوحات من الأن الندماج الأجناس

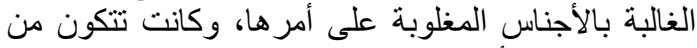

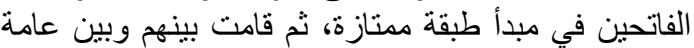
الشعب طبقة وسطى، وقد أخذ نفوذها يمتد شيئاً فثيئاً بما برعت فيه من العلوم والفنون والصنائع، وإنجاز الأعمال

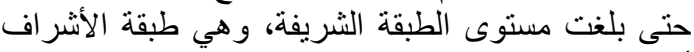

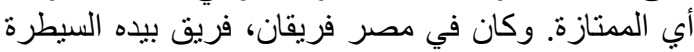

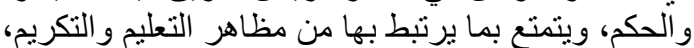

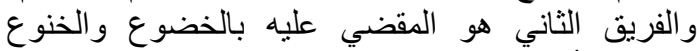

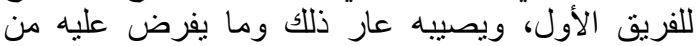

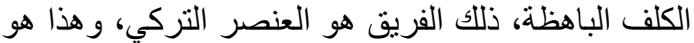
العنصر المصري العربي. ويستطرد "كلود بك الكي" قائلاً: أن أن

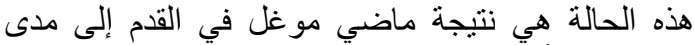

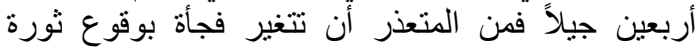

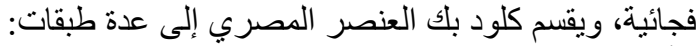

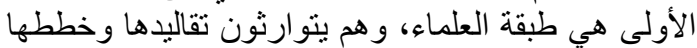

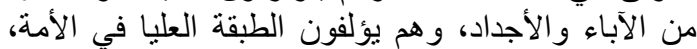

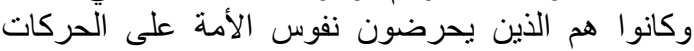

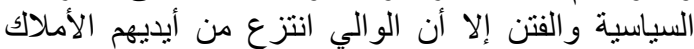

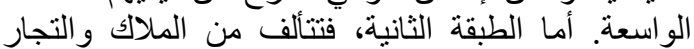

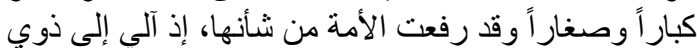

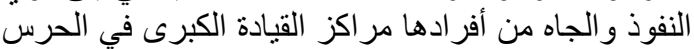

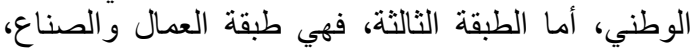

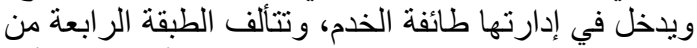

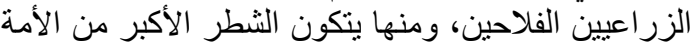

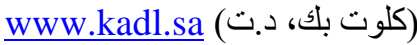

وأورد عبد الفضبل (1978) في كتابه التحولات

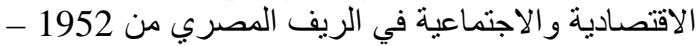

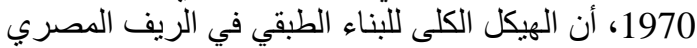

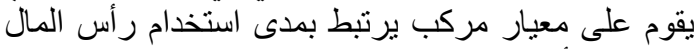

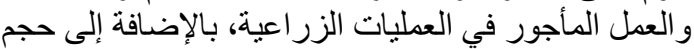

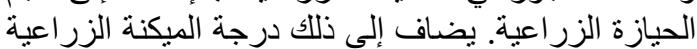

وجاههم، وأشار أيضاً إلى أن المهن التي ترتبط بحاجات

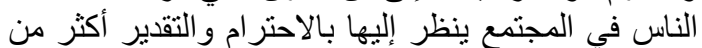

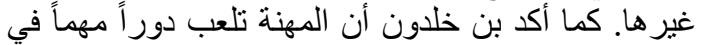

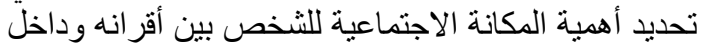

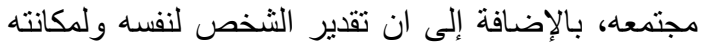

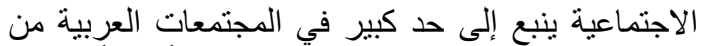

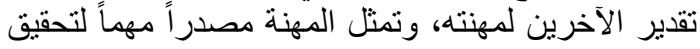
الذات للإنسان العامل (البوسعيدي، لمتين 2009)

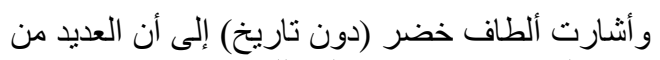

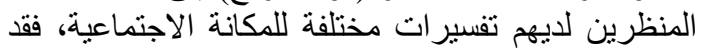

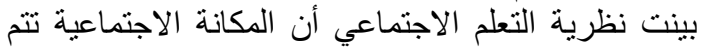

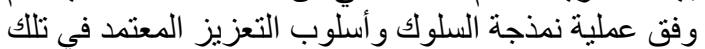

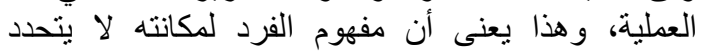

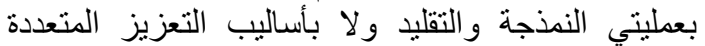

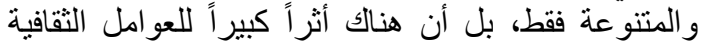
التي تختلف باختلاف السياقات الاجنماعية التي يعيش فيها الفرد.

أما أصحاب نظرية الدور فيشيرون إلى أن مفهوم

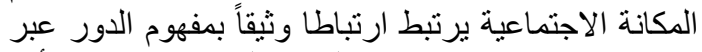

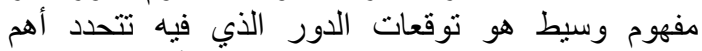
الواجبات والحقوق التي يمارسها الفرد في أداء دور فئه دعين

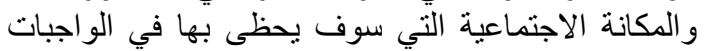
التي يلتزم بها والحقوق التي يسعى إلى نيلها لاعنى (سناء الخزرجي، 2010).

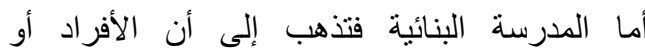

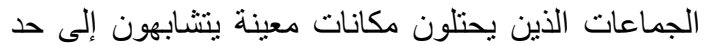

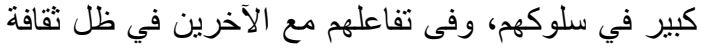

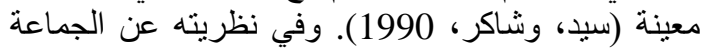

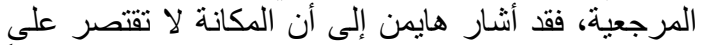

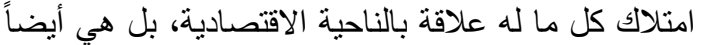

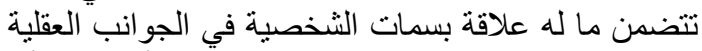

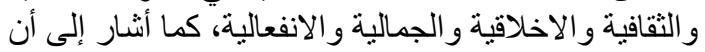

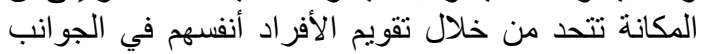

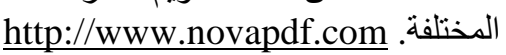

ويرى بومعالي (2011) أن الأسرة بوصفها مركزاً للعلاقات الاجتماعية، ومكان التربية والتنشئة الاجتئة الإنماعية،

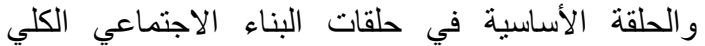

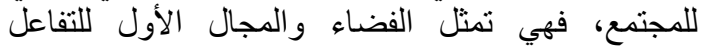

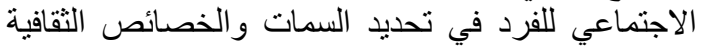

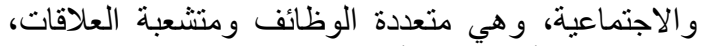

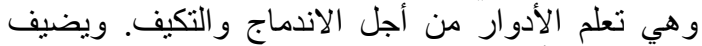
رشيد كذللك أن تحديد الدور وارد المكانة للفرد من الحتميات

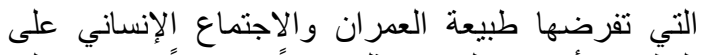

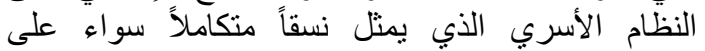
المستوى الثقافي أو النلطوي.

و عند الحديث عن معايير التطابق الاجتماعي،

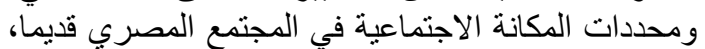

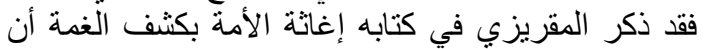




\section{A. M. Al-azab}

مما سبق عرضه،، يمكن القول إن المكانة الاجتماعية

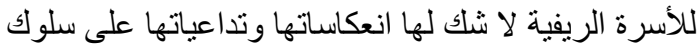

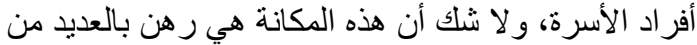

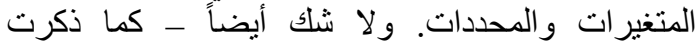

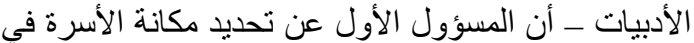

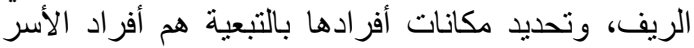

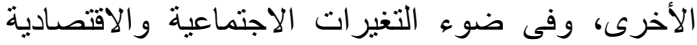

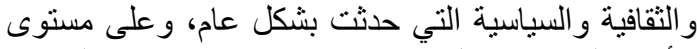

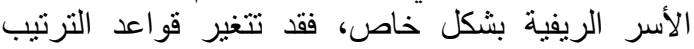

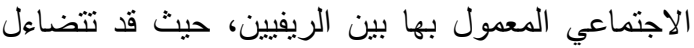

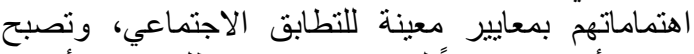

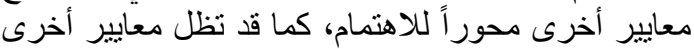

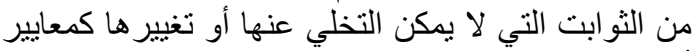

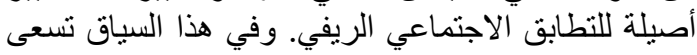

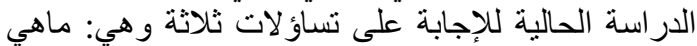

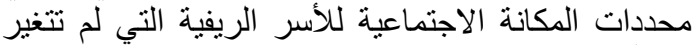

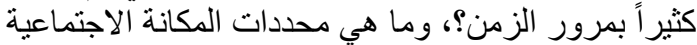

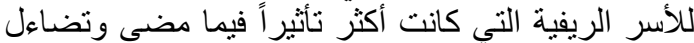

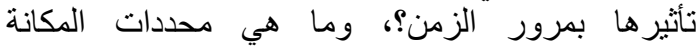
الاجتماعية للأسر الريفية التي ظهر تأثثير ها بوضوح في

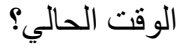

أهداف الار اسة

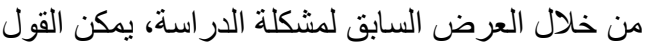
إن الدر اسة الحالية تسعى لتحقيق الأهداف الآتية:

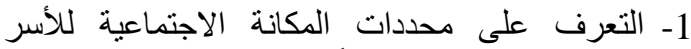

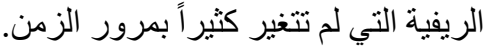

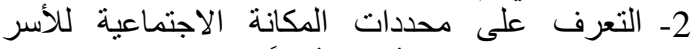

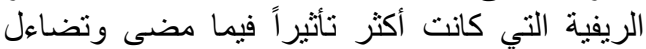
تأثنير ها بمرور الزية كان.

3- التعرف على بعر محددات الزكانة الاجتماعية للأسر الريفية التي ظهر تأثير ها بوضوح في الوقت الحالي.

\section{الطريقة البحثية

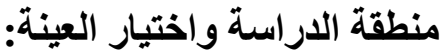

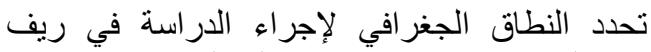

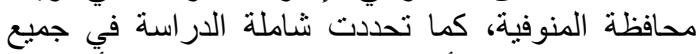

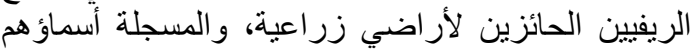

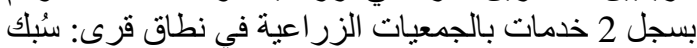

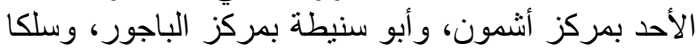

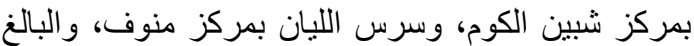

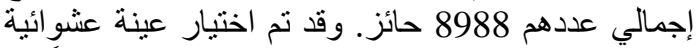

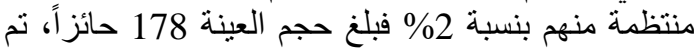

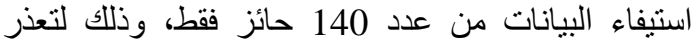

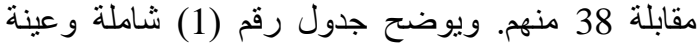
الدر اسة المبدئية و النهائية.

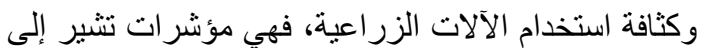

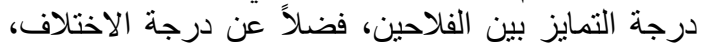

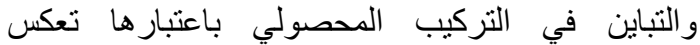

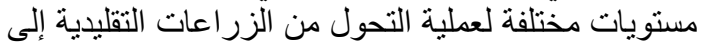

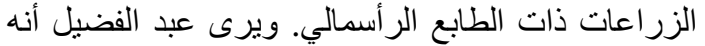

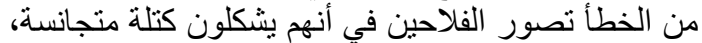
فهنالك تمايز طبقي بين المجموعات المختلفة من الفلاحين،

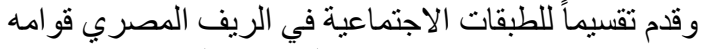

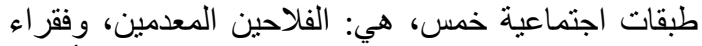
الفلاحين، وصغار الفلاحين، ومتوسطي الفيلاتحين، الفين، و أغنياء الفلاحين أو الر أسمالية الزراعية الفين، ودئ.

ويرى الخولي (2013) أن التركيبة الاجتماعية للقرية المصرية قديماً قد تضمنت عدد من الطبقات الاجتماعية الاعنة الترية

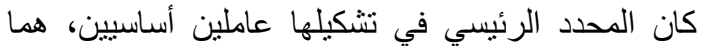

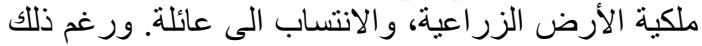

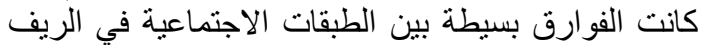

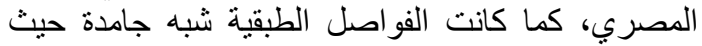

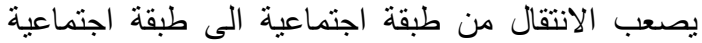

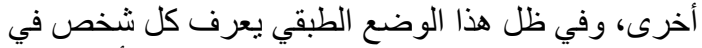

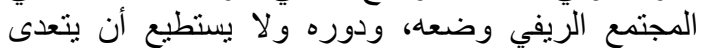

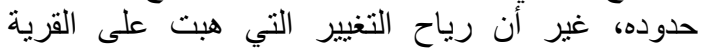

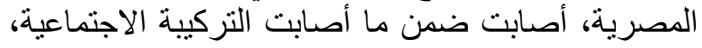

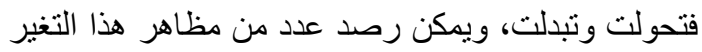

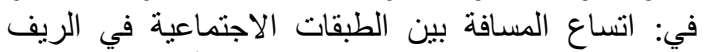

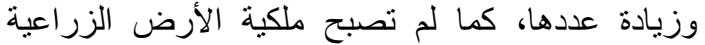

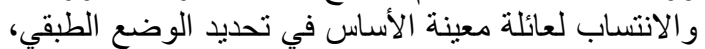

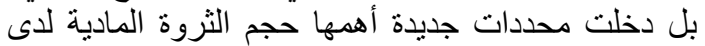

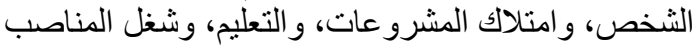

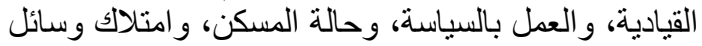

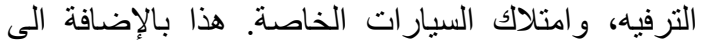

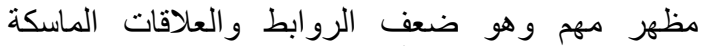

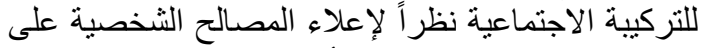

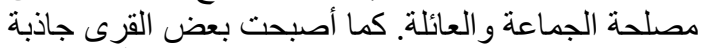

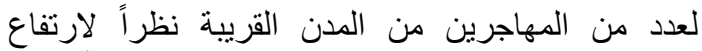

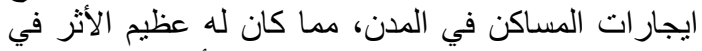

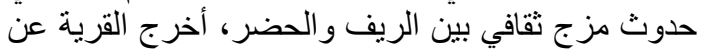

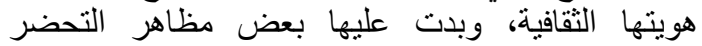
المزيف. ولعل أبرز العوامل التي أضعفت التهبة التركيبة

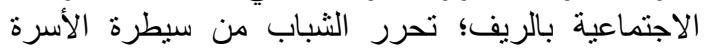

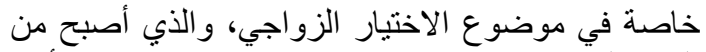

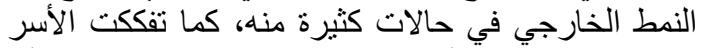

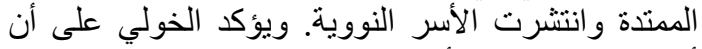
أبرز التغيرات التي أصابت التركيبة الاجتماعية وبخة وبناصة الديني منها، قد حدث إبان ثورة 25 يناير للعام 2011م.

جدول رقم (1): شاملة وعينة الدراسة

\begin{tabular}{|c|c|c|c|c|c|}
\hline العينة النهائية & العينة المبئية & الثشاملة & قرية & مركز & محافظة \\
\hline 60 & 61 & 3069 & سُبك الأحد & أشمون & المنوفية \\
\hline
\end{tabular}


Determinants of the social status of rural families in some Egyptian villages

\begin{tabular}{|c|c|c|c|c|c|}
\hline 17 & 19 & 966 & أبو سنيطة & الباجور & \\
\hline 13 & 15 & 776 & سلكا & شبين الكوم & \\
\hline 50 & 83 & 4177 & سرس الليان & منوف & \\
\hline 140 & 178 & 8988 & & الاجمالي & \\
\hline
\end{tabular}

ثم اخير اً من هم في فئة الحجم المرتفع (8 أفراد فأكثر)

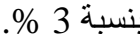

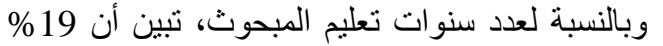

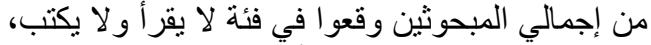

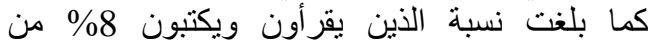
الإجمالي، والحاصلين على الثهادة الابتدائية 9 \% \% من من الإجمالي، والحاصلين على الثهادة الإعدادية 9 \% من من

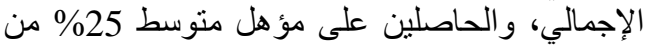

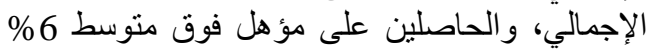

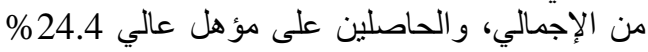

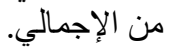

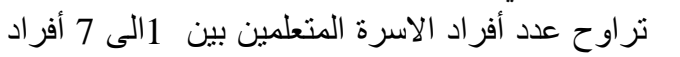
بمنوسط حسابي بلغ 4.2فرد، و انحر اف معياري 1.6 - مبالنسبة لحجم الحيازة المزرعية تبين أن الغالبية العظمى من المبحوثين يتركزون في فئة الحيازة (1 27 قير اط)، بينما 14 \% من المبحوثين قد تركزوا في

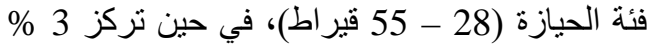
فقط من إجمالي المبحوثين في فئة الحيازة 65 قير اط تركز فأكثر. وبالنسبة لعدد سنوات خبرة المبحوث في الزراعة،

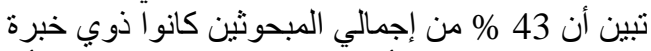

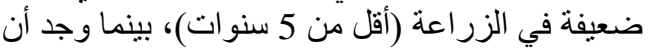

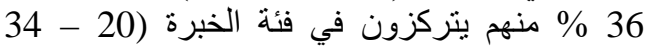

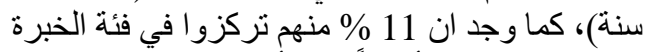

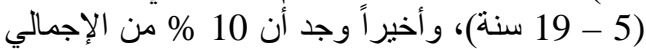
قد تركزو ا في فئة الخبرة (35 سنة فأكثر).

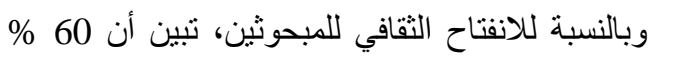

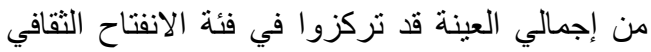

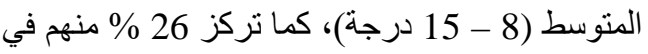

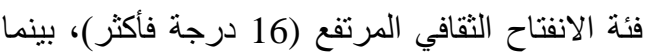
تركز 14 \% منهم في فئة الانفتاح الثقافي المنخفض (صفر - 7 درجات).

أداة جمع البيانات تم الاستعانة باستمارة الاستبيان بالمقابلة الثخصية

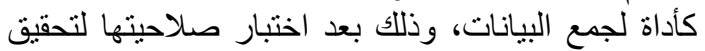

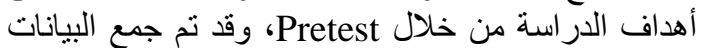
خلال شهر مارس من العام 2017م.

\section{قياس متغيرات الاراسة}

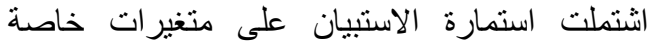

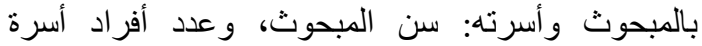

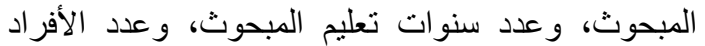

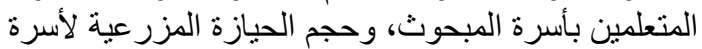

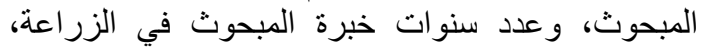

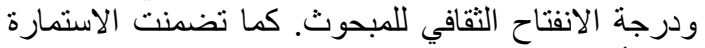

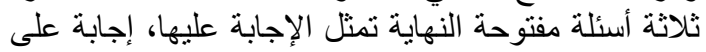

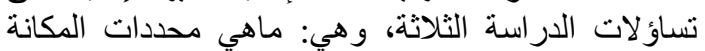

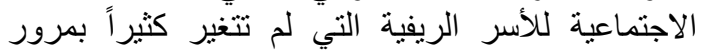

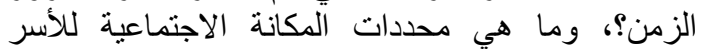

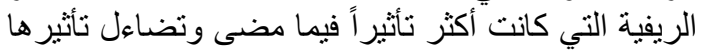

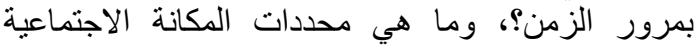
للأسر الريفية التي ظهر تأثيرها بوضوات التئح في الوقت

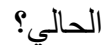

تم الاستعانة بأسلوب الإحصاء الإحساء الوصفي من خلال

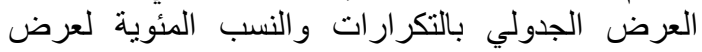

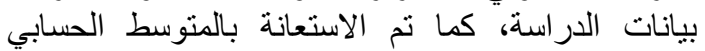
و الانحر اف المعباري لوصف أحد المتغيرات.

\section{وصف عينة الدراسة}

تبين من النتائج الواردة بالجدول رقم (2) والخاص بو ان كف عينة الدر استة ما يلي: - أن أكثر من نصف المبحوثين عينة الدراسة بنسبة 57 قد تركزو ا في الفئة العمرية (41 - 57 سنة سنة)، بلي ذللك من هم في الفئة العمرية (24 - 46 ـ 40 سنة بنسبة 36 \%، ثم اخير أ من هم في فئة (58 سنة فأكثر) بنسبة 7 \% \% \% كما تركز 68 \% من إجمالي المبحوثين عينة الدراسة في فئة حجم أسرة المنوسط (5 إسل

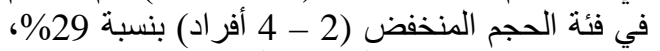
جدول رقم (2): وصف عينة الدراسة النة

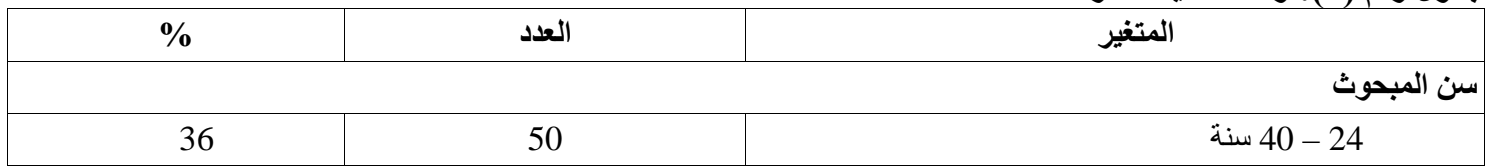




\section{A. M. Al-azab}

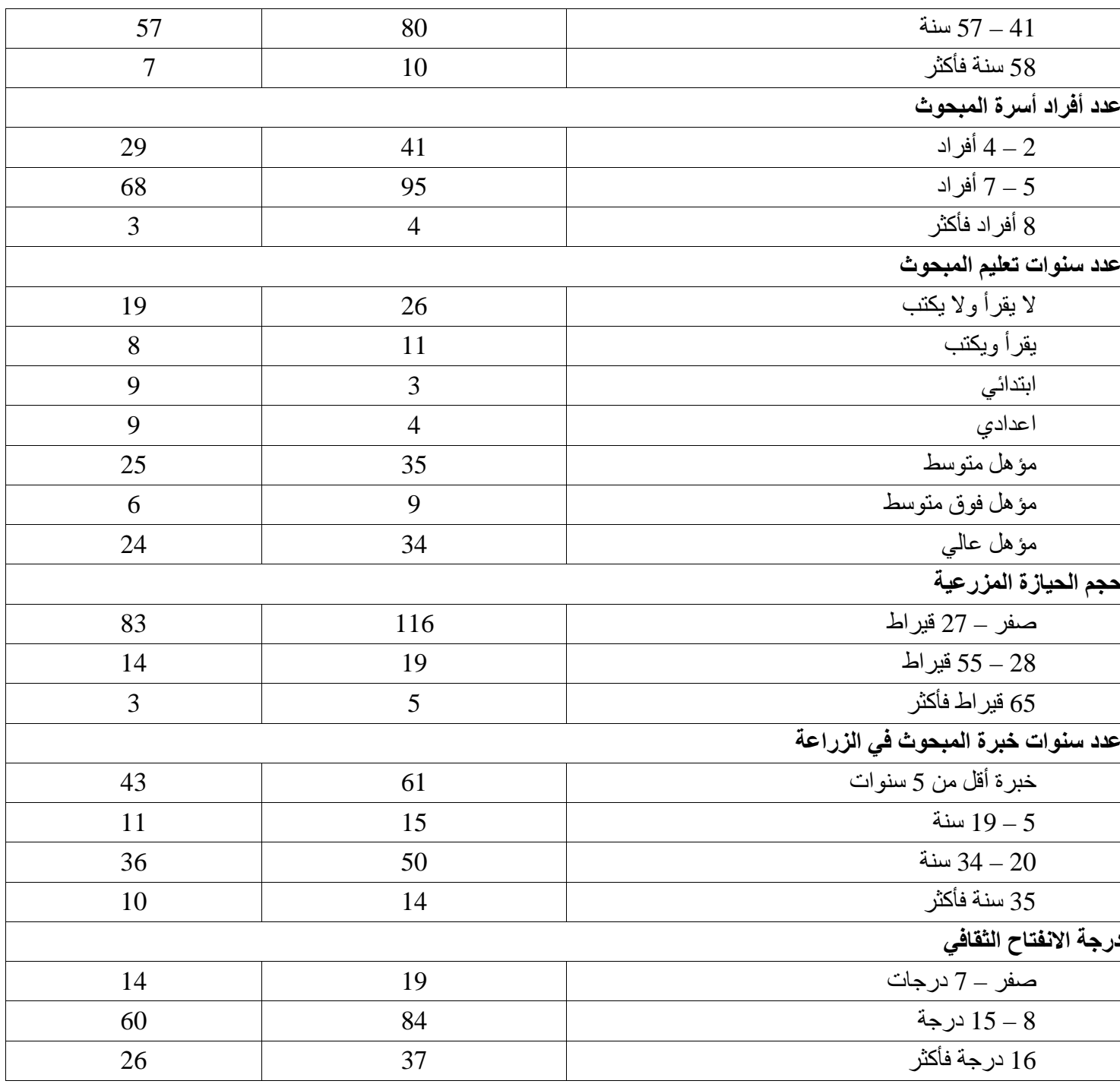

الزمن؟ وقد حصل الباحث على استجابات عديدة أمكن

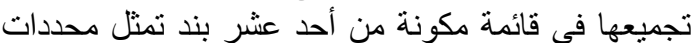

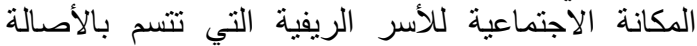

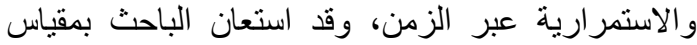
محددات المكانة الاجتماعية للأسرة الريفية الذية ألئية أعده سيد،

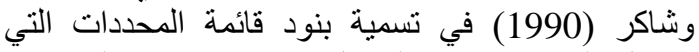
توصل اليها. ويوضح الجدول فئة رقم (3) قائمة المحددات مرتبة حسب أهميتها من وجهة نظر أفر اد عينة الدر اسة.
1 - محددات المكانة الاجتماعية للأسر الريفية التي

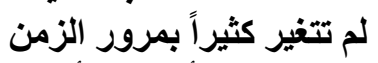

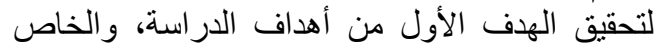
بالتعرف على محددات المكانة الاجتماعية للأسر الرفية الريفية

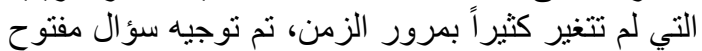

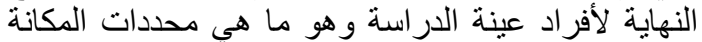

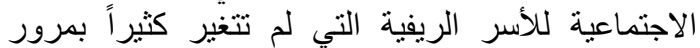

جدول رقم (3): التوزيع العددي والنسبي لأفراد عينة الدراسة حسب رؤيتهم لمحددات المكانة الاجتماعية للأسر الريفية

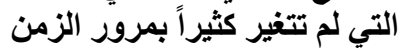

\begin{tabular}{|c|c|c|}
\hline$\%$ & 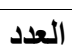 & قائمة محددات المكانة التي لم تتغير بمرور الزمن \\
\hline 91.4 & 128 & تعليم الأسرة \\
\hline 85.7 & 120 & دخل الأسرة \\
\hline 80.0 & 112 & سمعة الأسرة \\
\hline 68.6 & 96 & عضوية الأسرة بالمنظمات الاجتماعية \\
\hline
\end{tabular}




\begin{tabular}{|c|c|c|}
\hline 67.8 & 95 & العزوة الأسرية \\
\hline 67.1 & 94 & حجم الحيازة الزر اعبة للأسرة \\
\hline 63.6 & 89 & ر أس المال الاجتماعي للأسرة \\
\hline 62.9 & 88 & الوضع القيادي للأسرة \\
\hline 57.1 & 80 & المشاركة الاجتماعية غير الرسمية للأسرة \\
\hline 47.1 & 66 & حجم الحيازة الحيو انية للأسرة \\
\hline 40.0 & 56 & حالة مسكن الأسرة \\
\hline
\end{tabular}

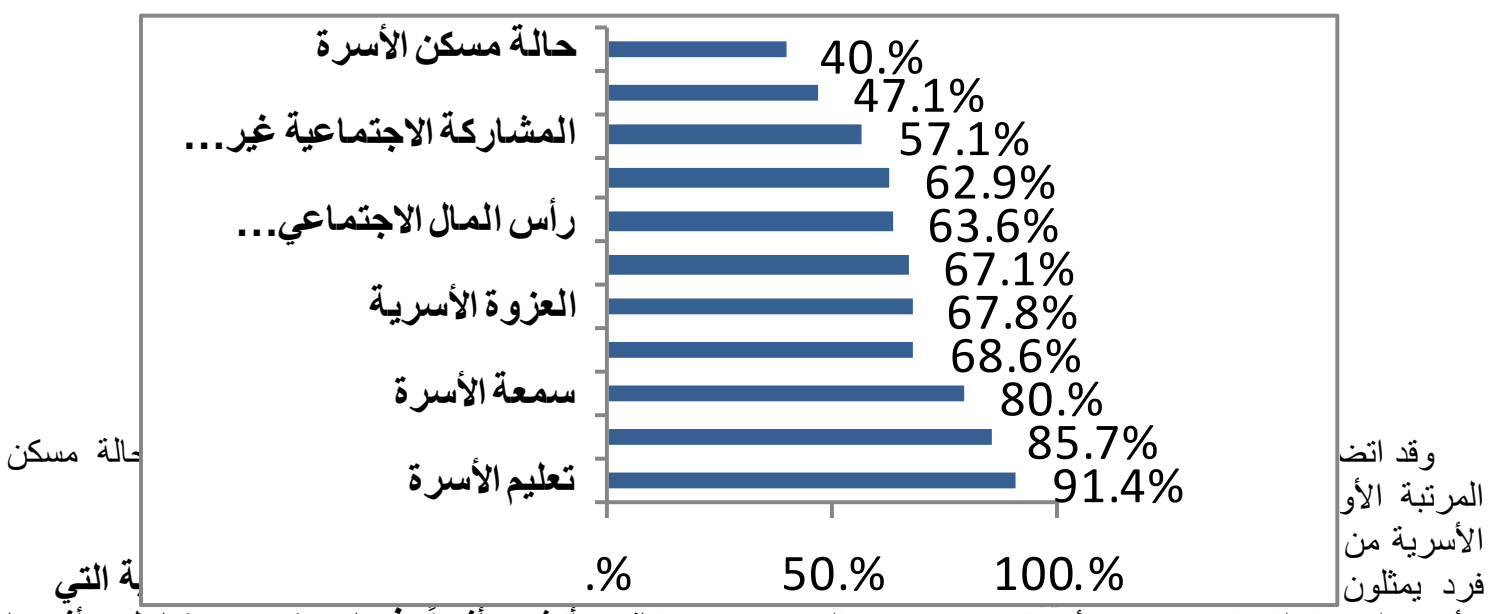

الأسرة المرتبة الثانية من حيث الأهمية (120 فرد يمثلون بمرور الزمن

لتحقيق الهدف الثاني من أهداف الدراسة والخاص

بالتعرف على محددات المكانة الاجتماعية للأسر الريفية

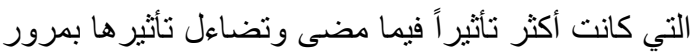
الزمن، يوضح الجدول رقم (4) آراء أفراد عينة الدراسة حول تلك المحددات والذي ينتين منه أن حيازة الأدوات التات والآلات الزراعية قد جاءت على رأس قائمة المدددات التي كانت مؤثرة في الماضي وتضاءل تأثير ها في الوقت

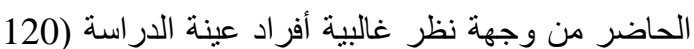
فرد يمثلون 85.7\% من الإجمالي)، بينما احتلت حيازة

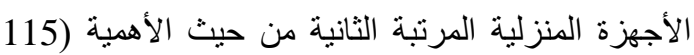
فرد يمثلون 82.1\% من الإجمالي)، كما جاء مستوى الأهئ

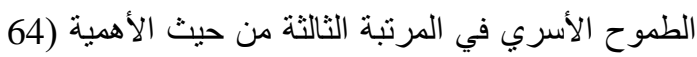
فرد يمثلون 45.7\% من الإجمالي)، في حين احتلت المكانة الاجتماعية لزوجة الابن أو زوج البنت البنت المرتبة الرابعة من حيث الأهمية (59 فرد يمثلون 42.1\% من الأن

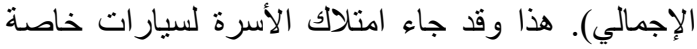
في المرتبة الخامسة والأخيرة من حيث الأهمية (42 فرد

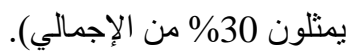

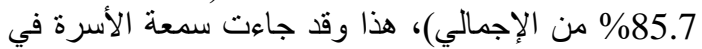

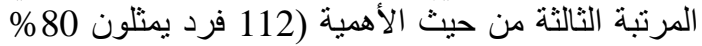

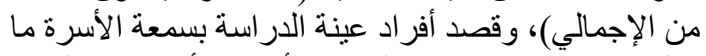

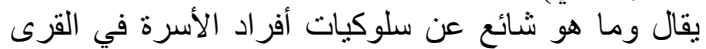

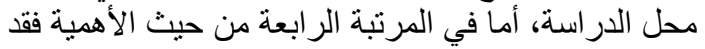

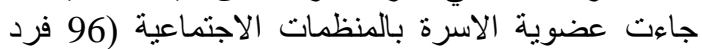
يمثلون 68.6\% من الإجمالي)، وفي المرتبة الخامسة من الإنة

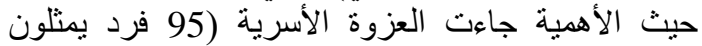

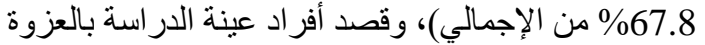

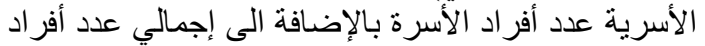

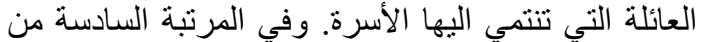

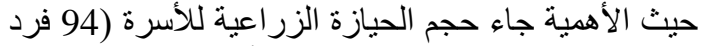

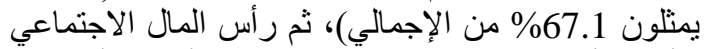

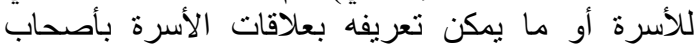

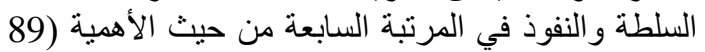

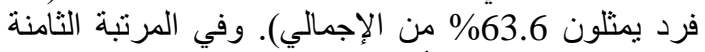

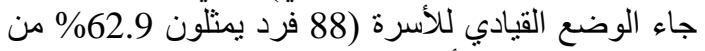

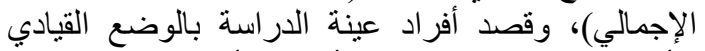

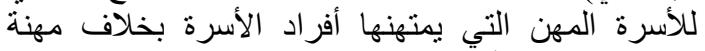

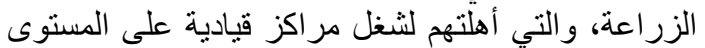

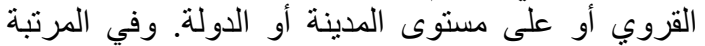

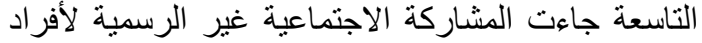
الأسرة وبخاصة الأعمال الخيرية لصالح أبناء القاء القرية (80)

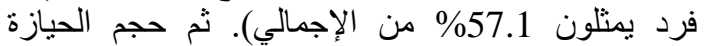

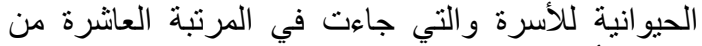

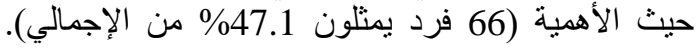




\section{A. M. Al-azab}

في الوقت الحالي من وجهة نظر غالبية أفراد عينة الدراسة (108 فرد يمثلون 77.1\% من الإجمالي)، بينما احتلت عضوية أحد أفراد الأسرة في المجالس المحلية أو مجلس النواب المرتبة الثانية من حيث الأهمية (100 فرد يمثلون

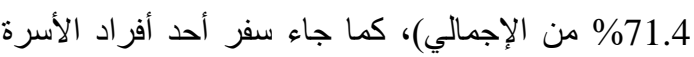

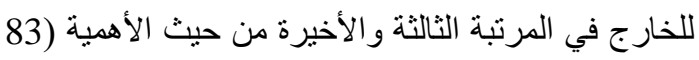

$$
\text { فرد يمثلون 59.3\% من الإجمالي). }
$$

3-محدات المكانة الاجتماعية للأسر الريفية التي

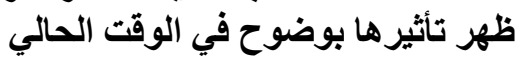
لتحقيق الهدف الثالث من أهداف الدراسة والخاص في لاص بالتعرف على محددات المكانة الاجتماعية للأسر الريفية

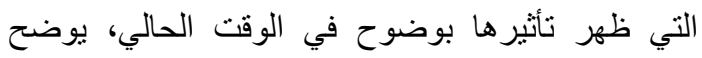
الجدول رقم (5) آراء أفراد عينة الدراسة حول تلأك المحدات و الذي يتبين منه أن الالتز ام الديني و الأخلاقي قد الدال

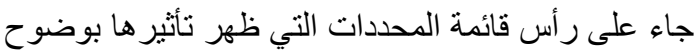
جدول رقم (4): التوزيع العددي والنسبي لأفراد عينة الدراسة حسب رأئر رؤيتهم لمحددات المكانة الاجتماعية للأسر الريفية

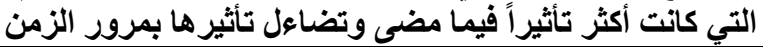

\begin{tabular}{|c|c|c|}
\hline$\%$ & العدد & قائمة محددات المكانة التي أكثر تأثيراً فيما مضى وتضاءل تأثير ها بمرور الزمن \\
\hline 85.7 & 120 & حيازة الأدوات و الآلات الزر اعية \\
\hline 82.1 & 115 & حيازة الأجهزة المنزلية \\
\hline 45.7 & 64 & مستوى الطموح الأسرى \\
\hline 42.1 & 59 & المكانة الاجتماعية لزوجة الأبن أو زوج البنت \\
\hline 30.0 & 42 & امتلاك الأسرة لسيار ات خاصة \\
\hline
\end{tabular}
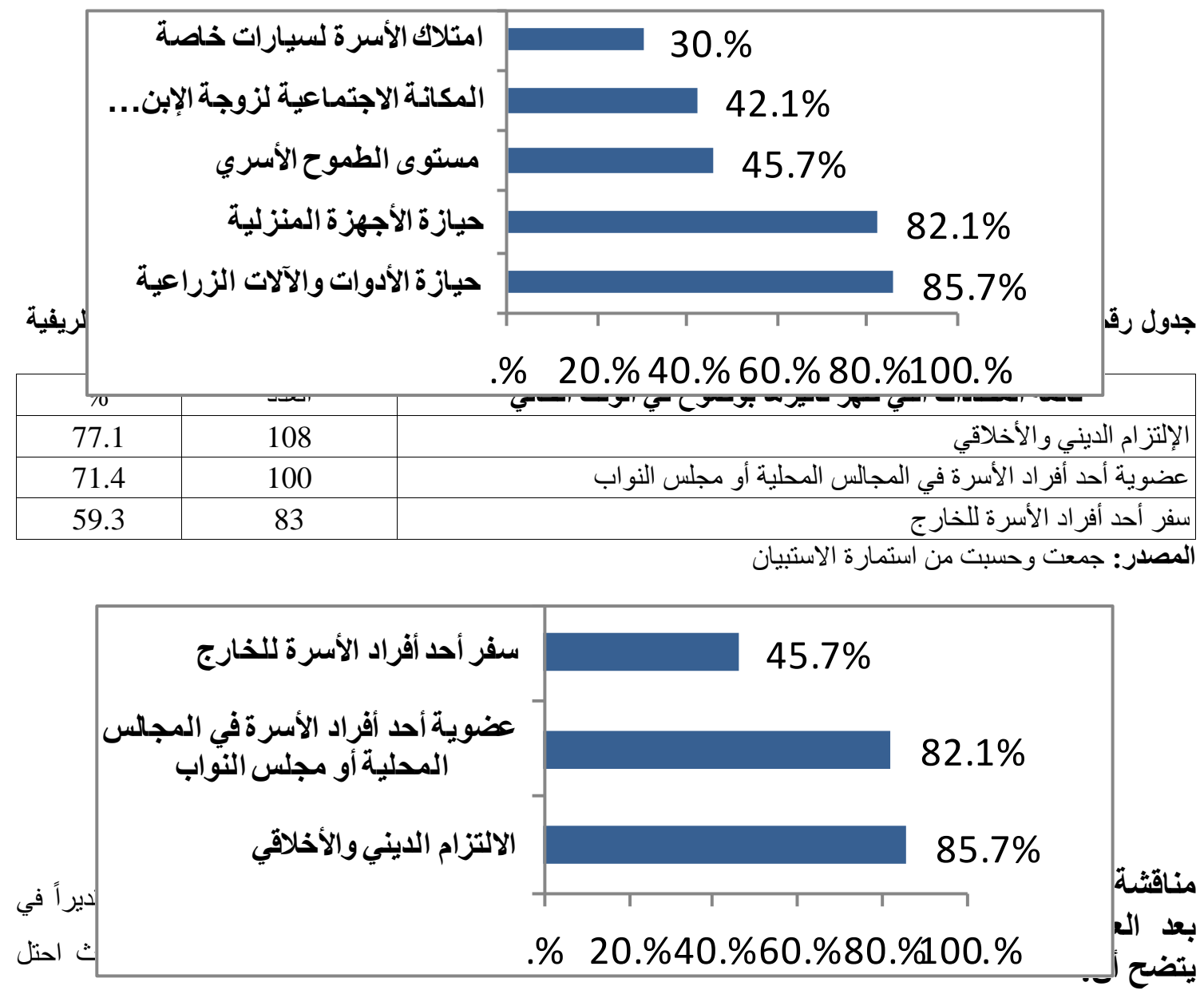
تحسن الحالة المسكنية للغالبية من سكان المناطق الريفية، الأمر الذي قلل الفوارق بينهم في شكل لئل المسكن ومستواه، وكذا الحال بالنسبة لاحتمال ازدياد حجم الحيازة الحيوانية لدى الغالبية، الأمر الذي يمكن في ضوئه تفسير تراجع رتبة هذين المحددين. 6- أما بخصوص معايير التطابق الريفي التي تراجع فئه

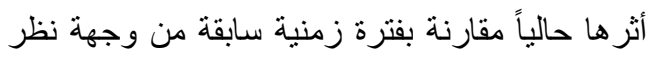
افراد عينة الدراسة، فقد جاء على رأس تلك المعايير

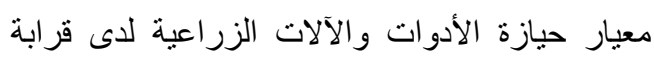
\%66 من الإجمالي، نلاه معيار حيازة الأجهزة

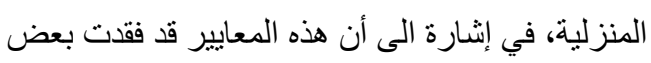
تأثير ها الطبقي بين الريفيين في الوقت الحالي.

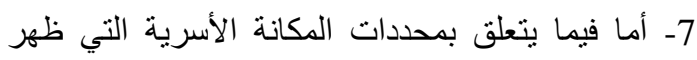
تأثنير ها جلياً في الوقت الحالي، فقد جاء على بلى رأسها الالتزام الديني والأخلاقي لدى أكثر من 75\% من هن

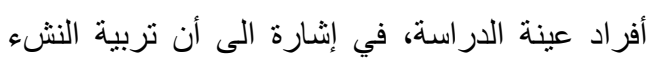

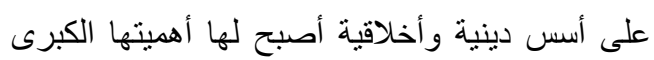
في الوقت الحالي كمعيار للترتيب الاجتماعي، في ظل العولمة والانفتاح الحضاري و الثقافي، و التغيرات السياسية والاقتصادية التي يشهدها المجتمع المصري

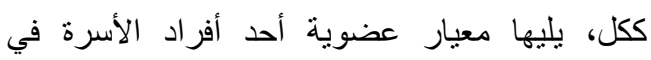
المجالس المحلية، أو مجلس النواب، في إثارة الى لى

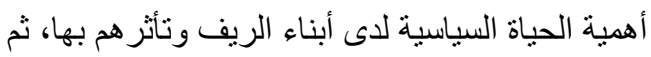

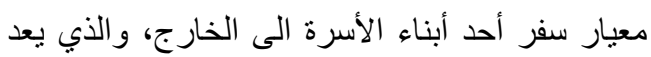

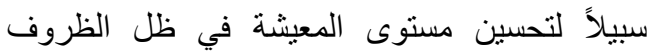
الاقتصادية الر اهنة.

وفي سياق ما تم عرضه ومناقشته من نتائج توصي

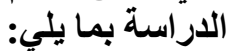

1- الاهتمام بتعليم كافة أبناء الريف، لما للتعليم من أهمية

$$
\text { كبرى في البنيان الطبقي الريفي بشكل عام. }
$$

2- إجراء مزيد من دراسات تحديد معايير وقياس الطبقة الاجتماعية في الريف المصري، مع أخذ النتائج التي دري
محدد تعليم الأسرة صدارة المحددات الأصيلة للمكانة الاجتماعية للأسر الريفية بغالبية لم يحققها محدد آخر من محددات المكانة (91.4\%). وتبدو هذه النتيجة

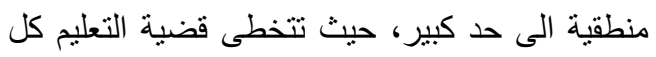

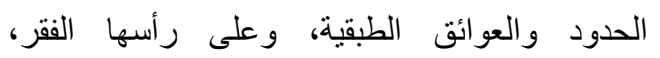
و الانتماء العائلي، وقضايا المظهر و المهنة، فحصول ولى ولئي

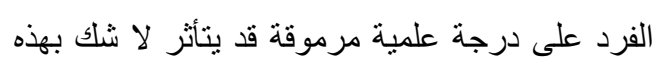

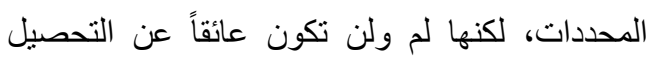
العلمي. ولا شك أن أبناء الريف قد خبن خبروا أهمية

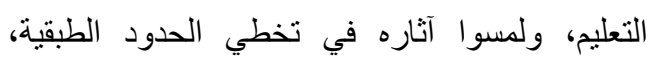
وارتقاء الافراد لسلم الحراك الاجتماعي، مما كان له عظيم الأثر في اختياره كأهم الحددات الأصيلة للتطابق الريفي. 2- أظهرت النتائج كذللك أهمية معيار الدخل كأحد معايير التطابق الريفي، حيث احتل المرتبة الثانية من حيث الثيث

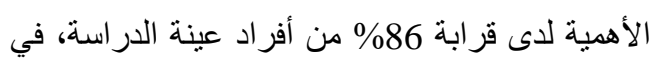

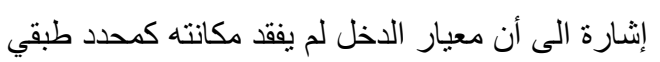
ريفي. كما جاء معيار السمعة في المرتبة الثالثة من لناري حيث الأهية لدى 80\% من أفراد عينة الدراسة، وتبدو أيضا هذه النتيجة هنطقية الى حد كبير، فمعياري لاني الدخل والسمعة من المعايير الأصيلة التي سيظل أبناء المجتمع الريفي يرتبون بعضهم البعض بناءً عليها.

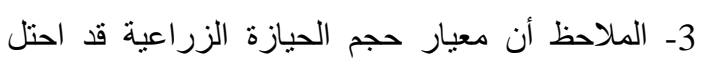
مرنبة متأخرة نو عاً ما مقارنة بمعايير التعليم والدخل مئل

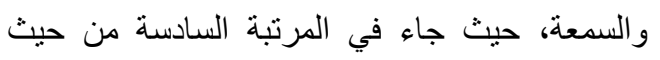

$$
\text { الأهمية لدى نحو تلثي عينة الدراسة. }
$$

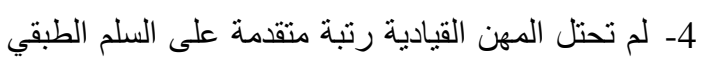

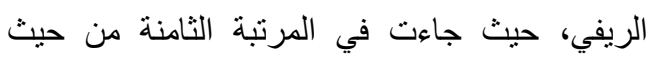
الأهية لدى قرابة 63\% من أفراد عينة الدر اسة.

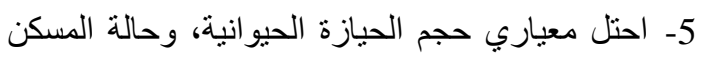
المرتبتين قبل الأخبرة، والأخبرة على على الترتيب كحددات طبقية ريفية أصيلة، وربما يثير ذلك الى ولى الائي 


\section{A. M. Al-azab}

- بومعالي، رشيد، و اقع التغيرات الاجتماعية في الأسر

الريفية الجزائرية المهاجرة، سلسلة دراسات

اجتماعية، المجلد السابع، العدد التاسع والخمسين،

.2011

- خضر، ألطاف ياسين، الذكاء الانفعالي و علاقته بالمكانة الاجتماعية لدى موظفات جامعة بغداد، مجلة البحوث التربوية والنفسية، العدد الثاني و الثلاثون،

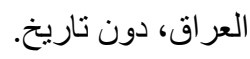

- رشوان، حسين عبد الحميد أحمد، التظيم الاجتماعي والمعايير الاجتماعية، مؤسسة شباب الجامعة، الإسكندرية،2014. - - سيد، أحمد جمال الدين، وأسامة أبو المكارم شاكر، نحو بناء قائمة لقياس المكانة الاجتماعية للأسرة الريفية المصرية، دراسة ميدانية على قرية نواي بمحافظة المنيا، مجلة البحوث والتنمية الزراعية بالمنيا، كلية الزراعة جامعة المنيا، المجلد 12، العدد

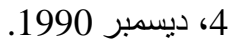
- عبد الفضيل، محمود، التحولات الاقتصادية و الاجتماعية في الريف المصري (1952 - 1970): دراسة في تطور المسألة الزراعية في مصر، الهيئة المصرية العامة للكتاب، 1978. - عبد الله، شادية محمد بينين، محددات المكانة الاجتماعية في المجتمع الحضري السوداني، رسالة دكتور اه، كلية الآداب، قسم الاجتماع، جامعة أم درمان الإسلامية، السودان، - عمر، معن خليل، انشطار المصطلح الاجتماعي، وزارة التعليم العالي و البحث العلمي، بغداد، 1990. - غيث، محمد عاطف، قاموس علم الاجتماع، دار المعرفة الجامعية، الإسكندرية، 2006. - فرحات، كرم حلمي، در اسة وتحقيق لكتاب إغاثة الأمة بكثف الغمة للعلامة تقي الدين ابن عباس أحمد ابن
توصلت اليها الدراسة الحالية بعين الاعتبار وذلك لتحديث مقاييس المكانة المستخدمة بالإبقاء على معايير التطابق الأصيلة، ودمج المعايير ذات التأثير الواضح في الوقت الحالي، و استبعاد المعايير التي لم تعد مؤثرة كسابق عهدها في الماضي، فوجود معايير واضحة متفق عليها من الغالبية العظمى من سكان مناطق ريفية أخرى، من شأنه أن يحقق اتساقاً أفضل في المكانة الاجتماعية للريفيين، ومن ثم رسم صورة أكثر و اقعية لطبيعة التدرج الاجتماعي في الريف المصري. المراجع - البوسعيدي، راثد بن حمد بن حميد، تقدير طلبة جامعة السلطان قابوس للمكانة الاجتماعية للمهن الثائعة في المجتمع العماني، المجلة الأردنية للعلوم الاجتماعية، المجلد الثاني، العدد الأول، الأردن، 2009. - البياتي، فر اس عباس فاضل، دو افع تفضيل المهن لدى السكان، دراسة سوسيو ديموغرافية في المكانة الاجتماعية للمهنة، مجلة شؤون اجتماعية، العدد 98،

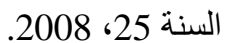
- الخزرجي، سناء علي حسون، الكفاية المهنية لاى المرشدين التربويين وعلاقتها بالمكانة الاجتماعية، رسالة ماجستير، كلية التربية، جامعة ديالي، العراق، .2010

- - - - الخولي، الخولي إبراهيم سالم، التركيبة الاجتماعية و الأوضاع الر اهنة في الريف، سلسلة الأرض والفلاح الصادرة عن مركز الأرض لحقوق الانسان، العدد 70، القاهرة، نوفمبر 2013. - الطويل، هشام، وعباطة التوايهة، بعض المتغيرات الديموغر افية و أثرها في المكانة الاجتماعية للمهنة، مجلة العلوم الاجتماعية، العدد 3، 2001. - العزب، أثرف محمد، محاضرات في الطبقات الاجتماعية، كتاب جامعي غير منشور، النور للطباعة، كفر الثيخ، 2008. 


$$
\begin{aligned}
& \text { على المقريزي، عين للاراسات والبحوث الإنسانية مبارك، بشرى، التعصب وعلاقته بالهوية الاجتماعية } \\
& \text { و الاجتماعية، الطبعة الأولى، الجيزة، 2007. المكانة الاجتماعية لاى العاطلين عن العمل، مجلة }
\end{aligned}
$$

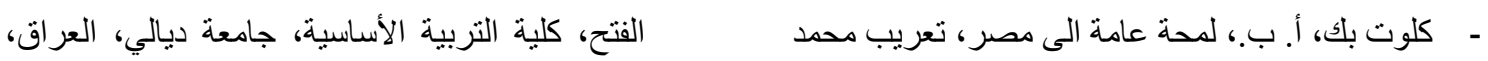

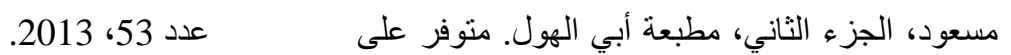

$$
\begin{aligned}
& \text { http://www.novapdf.com - مدكبة }
\end{aligned}
$$

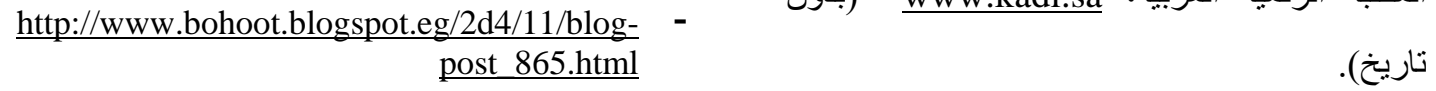

\title{
DETERMINANTS OF THE SOCIAL STATUS OF RURAL FAMILIES IN SOME EGYPTIAN VILLAGES
}

\author{
A. M. Al-azab \\ Assistant Professor of Rural Sociology - Kafrelsheikh University
}

\begin{abstract}
The study aimed at identifying the social status of rural families in some Egyptian villages by answering three questions: What are the determinants of the social status of rural families that have not changed much over time? What are the determinants of the social status of rural families that were more influential in the past and their impact diminished over time? What are the determinants of the social status of rural families whose impact has now become apparent? The geographical scope of the study was determined in the rural areas of Menoufia Governorate. The study was also conducted in all rural areas holding agricultural land registered with 2 services in the agricultural associations in the villages of Sabek Sunday in Ashmoun Center, Abu Snieta in El Bagour Center, Silka in Shebin El Koum Center, In the center of Menouf, a total of 8988 holders. A random sample of $2 \%$ was selected, with a sample size of 178 holders. Data were collected from 140 holders.
\end{abstract}

The results of the study showed: 


\section{A. M. Al-azab}

1. The issue of education still occupies a prominent place in the rural population and has not changed over time. The determinants of family education have become the main determinants of the social status of rural families, with a majority of $91.4 \%$.

2 - The results also showed the importance of the income criterion as one of the criteria of rural matching, where it ranked second in terms of importance in nearly $86 \%$ of the sample of the study.

3. It is noted that the criterion of the size of agricultural tenure has ranked somewhat late compared to the standards of education, income and reputation, ranked sixth in terms of importance in about two-thirds of the sample of the study.

4. The leadership professions did not occupy an advanced rank on the rural class ladder, which came in eighth place in terms of importance in about $63 \%$ of the sample members of the study.

5. The standard of animal possession, the status of the penultimate dwelling, and the last, respectively, were categorized as authentic rural class determinants.

6. In terms of the criteria for rural matching, which are currently being reviewed compared to a previous period from the point of view of the study sample members, the criteria for the acquisition of agricultural tools and machinery reached $86 \%$ of the total, followed by the standard of possession of household appliances.

7. In terms of the determinants of family status, the religious and moral commitment of more than $75 \%$ of the study sample, followed by the standard of membership of a family member in the local councils or the House of Representatives, One of the sons of the family abroad.

In the context of what was presented and discussed the results of the study recommended the following:

1 - Interest in the education of all rural people, because of the importance of education in the rural class structure in general.

2. Further studies to determine the criteria and measurement of the social class in the Egyptian countryside, taking into consideration the findings of the current study, to update the status criteria used to maintain the original conformity criteria, to incorporate the currently clear criteria and to exclude the criteria that no longer exist The existence of clear criteria agreed upon by the vast majority of the population of other rural areas would achieve a better consistency in the social status of rural people and thus a more realistic picture of the nature of social gradation in rural Egypt.

Key words: Social Status, Rural Families, Rural Social Classes. 